\title{
Chromatographic Determination of Phenolic Acids and Flavonoids in Lycium barbarum L. and Evaluation of Antioxidant Activity
}

\author{
Sylwia Magiera $^{1} \cdot$ Michal Zaręba $^{1}$
}

Received: 4 November 2014 / Accepted: 30 March 2015 / Published online: 17 April 2015

(C) The Author(s) 2015. This article is published with open access at Springerlink.com

\begin{abstract}
Polyphenols are the important active compounds present in the fruits of Lycium barbarum L. The objectives of this study were to develop an ultra-high performance liquid chromatography with UV detection (UHPLC-UV) method for qualitative and quantitative analyses of phenolic acids and flavonoids in fruits of $L$. barbarum L. The isolation and enrichment of polyphenols from fruits were carried out by ultrasound-assisted extraction (UAE) in conjunction with solid-phase extraction (SPE). The analytes were separated on a Poroshell 120 EC-C18 column using a binary mobile phase composed of aqueous $0.05 \%$ trifluoroacetic acid and acetonitrile in the gradient elution mode. Under these conditions, phenolic acids and flavonoids were separated in $11 \mathrm{~min}$. The selectivity of the developed UHPLC-UV method was confirmed by comparison with ultra-high performance liquid chromatography-tandem mass spectrometry (UHPLCMS/MS) analysis. The validation parameters such as linearity, sensitivity, precision, and accuracy were found to be highly satisfactory. The optimized method was successfully applied to the analysis of polyphenols in fruits of L. barbarum L. Additionally, their free radicalscavenging activity was assessed by 1,1-diphenyl-2picrylhydrazyl radical $\left(\mathrm{DPPH}^{\circ}\right)$.
\end{abstract}

Electronic supplementary material The online version of this article (doi:10.1007/s12161-015-0166-y) contains supplementary material, which is available to authorized users.

Sylwia Magiera

sylwia.magiera@polsl.pl

1 Department of Inorganic, Analytical Chemistry and Electrochemistry, Silesian University of Technology, 7 M. Strzody Str., 44-100 Gliwice, Poland
Keywords Lycium barbarum L · Phenolic acid · Flavonoid · Liquid chromatography

\section{Introduction}

As sources of natural antioxidants, much attention has been paid to plants. Lycium barbarum L. is one of the most important traditional Chinese medicinal plant species. Fruits and leaves of $L$. barbarum L. were widely used as vegetable medicines and functional tea in China, Southeast Asia, Europe, and North America. Most of its functions were reported as immunity improvement, anti-oxidation, anti-radiation, anticancer, enhancing hemopoiesis, anti-aging, and enhancing sex. The presence of various functional components like polysaccharides, flavonoids, and carotenoids in L. barbarum L. fruits is believed to be responsible for these effects (He et al. 2012; Yao et al. 2011). Several physiological studies have focused on polysaccharides and carotenoids; however, flavonoids have been less investigated, especially for their antioxidant activity (Amagase and Farnsworth 2011; Potterat 2010).

Flavonoids, a class of polyphenol compounds, are widely distributed in plants, especially fruits and vegetables. More than 6000 flavonoids have been characterized in nature, but their variety and amount differ because of differences in growing environments, maturity, and growth conditions. They comprise of flavones, flavonols, flavanols, flavanones, and flavanonols and represent the majority of plant secondary metabolites. Flavonoids play an important role in protection of plants from microbial and insect attack. Flavonoids also protect against UV-B radiation (Harborne and Williams 2000). Moreover, flavonoids have remarkable health promoting effects, such as anti-inflammatory, anti-microbial, antioxidant, anti-cancer activity, as well as the prevention of osteoporosis (Cushnie and Lamb 2011; Daglia 2012; Mulvihill and Huff 
2010; Procházková et al. 2011; Shalaby et al. 2011). Similarly, phenolic acids have received considerable attention because of their protective role against cancer and heart diseases. Recent interest in phenolic acids stems from their potential protective role, through ingestion of fruits and vegetables, against oxidative damage diseases (coronary heart disease, stroke, and cancers). This also may be attributed to their antioxidant activity which was reported to be higher than the vitamin antioxidants (Cartea et al. 2011). In view of the impact of both phenolic acids and flavonoids on human health, it is essential to learn about their amounts and varieties in medicinal plants (Bravo 1998; Scalbert and Williamson 2000).

Few techniques have been described in the literature for determining the phenolic acid and flavonoid content in L. barbarum L. extracts. These techniques include highperformance liquid chromatography (HPLC), as the most efficient and robust specific technique due to some advantages including convenience, simple operation, strong separation ability, and wide sample application. Two detection techniques have been used to accurately determine the concentration of polyphenols in fruits of $L$. barbarum L.; these techniques include mass spectrometry (MS) and UV (Dong et al. 2009; Inbaraj et al. 2010; Le et al. 2007; Qian et al. 2004; Wu et al. 2012). The separation of three flavonoids was also obtained with capillary electrophoresis with amperometric detection (Duan et al. 2010).

Recently, there has been a trend to improve the quality of the chromatographic separation through the utilization of columns with smaller diameter particles. In ultra-high performance liquid chromatography (UHPLC), columns packed with sub- $2 \mu \mathrm{m}$ particles are used, and when combined with the elevated operating pressures, can result in a significant reduction in retention times. With current UHPLC systems, analysis times can be decreased by a factor of 9 when compared to HPLC analysis. The negative effect of particle decrease is back-pressure increase. Other advantages of UHPLC include greater sensitivity because of the sharper peak profile and reduced solvent consumption due to the shorter cycle times. This latter advantage has increased in significance as global prices for acetonitrile, one of most common mobile phase components, have skyrocketed. Solvent consumption reductions of greater than $80 \%$ are frequently achieved with UHPLC (Nováková et al. 2006).

In this study, a simple and rapid UHPLC-UV method was established and validated to determine the polyphenols present in fruits of $L$. barbarum L.: 3,4-dihydroxybenzoic acid, 4hydroxybenzoic acid, 3-hydroxybenzoic acid, hippuric acid, caffeic acid, vanillic acid, 4-hydroxy-3-methoxyphenylacetic acid, 3-(2,4-dihydroxyphenyl) propionic acid, $p$-coumaric acid, ferulic acid, $( \pm)$-catechin, (-)-epicatechin, rutin, quercitrin, hesperidin, neohesperidin, $( \pm)$-naringenin, hesperetin, chrysin, and pinocembrin. The validated method was applied to qualitative and quantitative determination of phenolic acids and flavonoids in fruits of $L$. barbarum L. Also, the identity of the polyphenols in samples was confirmed by ultra-high performance liquid chromatography-tandem mass spectrometry (UHPLC-MS/MS) method in multiple reaction monitoring (MRM) mode. Moreover, in the present study, the antioxidant activities of extracts of $L$. barbarum L. were evaluated.

\section{Material and Methods}

\section{Chemicals and Reagents}

Phenolic acid standards, including 3,4-dihydroxybenzoic acid (3,4-DHBA), 4-hydroxybenzoic acid (4-HBA), 3hydroxybenzoic acid (3-HBA), hippuric acid (HA), caffeic acid (CA), vanillic acid (VA), 4-hydroxy-3-methoxyphenylacetic acid (HVA), 3-(2,4-dihydroxyphenyl) propionic acid (DHPA), $p$-coumaric acid ( $p$-CA), and ferulic acid (FA), were obtained from Sigma (St. Louis, MO, USA). Flavonoid standards, including $( \pm)$-catechin hydrate $(( \pm)-\mathrm{CA}),(-)$-epicatechin $((-)$ $\mathrm{EC})$, rutin (RUT), quercitrin (QUR), hesperidin (HSD), neohesperidin (NHSD), $( \pm)$-naringenin $(( \pm)-\mathrm{NAR})$, hesperetin (HST), chrysin (CHS), pinocembrin (PIN), and biochanin A (BIO), were also purchased from Sigma. 2,2-diphenyl-1-picryl hydrazyl (DPPH') was obtained from Sigma-Aldrich (St. Louis, MO). The HPLC-grade solvents water, acetonitrile, and trifluoroacetic acid (TFA) were obtained from Merck (Darmstadt, Germany). Analytical-grade methanol, ethanol, and hydrochloric acid were purchased from POCH S.A. (Gliwice, Poland).

\section{Standard Solutions, Calibration Standards, and Quality Control Sample}

All stock standard solutions $\left(1 \mathrm{mg} \mathrm{mL} L^{-1}\right)$ of phenolic compounds were prepared by dissolving an appropriate amount in methanol. From these stock solutions, a working solution containing adequate concentrations of all the analytes in methanol was prepared.

Calibration standard (CS) solutions at six concentrations of polyphenols (concentration range from 0.2 to $20 \mu \mathrm{g} \mathrm{mL}^{-1}$ for 3,4-DHBA, CA, NHSD, HSD, PIN, ( \pm )-CA, NAR and from 0.3 to $30 \mu \mathrm{g} \mathrm{mL}^{-1}$ for 4-HBA, HA, VA, 3-HBA, HVA, (-)EC, DHPA, $p$-CA, FA, RUT, QUR, HST, CHS) were obtained by appropriate dilutions of working stock solution in mobile phase $(0.05 \%$ TFA in water:acetonitrile $(90: 10 ; v / v))$.

Quality control (QC) samples were prepared in mobile phase $(0.05 \%$ TFA in water:acetonitrile $(90: 10 ; v / v))$ at three concentration levels: low-quality control (LQC): 1.0 $1.5 \mu \mathrm{g} \mathrm{mL}^{-1}$; middle-quality control (MQC): 10.0 $15.0 \mu \mathrm{g} \mathrm{mL}^{-1}$; and high-quality control (HQC): $16.7-$ $20.0 \mu \mathrm{g} \mathrm{mL}{ }^{-1}$. All solutions were stored in glass-stoppered bottles in the dark at $4{ }^{\circ} \mathrm{C}$. 


\section{Apparatus and Chromatographic Conditions}

The chromatographic separation of the analytes was performed using UHPLC system (Merck Hitachi, Germany) equipped with a pump (Model L-2160U), UV detector (Model L-2400U), autosampler (Model L-2200), temperature-controlled column compartment (Model L-2350U), and a degasser module. EZ Chrom Elite System Manager was used for instrument control and data acquisition.

Chromatographic separations were performed on a Poroshell 120 EC-C18 analytical column $(100 \mathrm{~mm} \times$ $3.0 \mathrm{~mm} ; 2.7 \mu \mathrm{m}$, Agilent Technologies, USA) operated at $30{ }^{\circ} \mathrm{C}$. A binary gradient consisting of (A) $0.05 \%$ TFA in water and (B) acetonitrile was employed to achieve chromatographic separation and is defined in Table 1. The injected volume was $2 \mu \mathrm{L}$. Monitoring and quantitation were performed at $230 \mathrm{~nm}$ for DHPA, 3-HBA, (-)-EC, HA, HVA, $( \pm)-C A$, QUR; at $260 \mathrm{~nm}$ for 3,4-DHBA, 4-HBA, CHS, RUT, VA; at $285 \mathrm{~nm}$ for HSD, HST, NAR, NHSD, PIN; and at $310 \mathrm{~nm}$ for CA, $p$-CA, FA. Using these conditions, 20 studied polyphenols and BIO (internal standard, IS) were successfully separated within $11 \mathrm{~min}$.

The individual compounds were identified by comparing their retention time, and their identification was confirmed by the standard addition method.

In addition, the confirmatory UHPLC-MS/MS analysis was performed using Dionex UPLC system (Dionex Corporation, Sunnyvale, CA, USA) coupled with an AB Sciex Q-Trap ${ }^{\circledR} 4000$ mass spectrometer (Foster City, CA, USA). The chromatographic separation was performed using the column and gradient elution program described above, except for the application of TFA in the mobile phase. TFA strongly suppresses ionization in the negative ion mode, and so $0.1 \%$ formic acid in water was used as a component of the mobile phase if an MS/MS detector was employed during sample analysis.

MS/MS conditions were applied as described previously by Magiera et al. 2012. Mass spectrometer with a TurboIonSpray source was performed in negative ion mode.

\begin{tabular}{llll}
\cline { 2 - 3 } $\begin{array}{l}\text { Table 1 Time- } \\
\text { scheduled gradient } \\
\text { elution program }\end{array}$ & $\begin{array}{l}\text { Time } \\
(\mathrm{min})\end{array}$ & $\begin{array}{l}\text { Mobile phase } \\
\text { composition }\end{array}$ & $\begin{array}{l}\text { Flow rate } \\
(\mathrm{mL} \mathrm{min})^{-1}\end{array}$ \\
\cline { 2 - 3 } & $\mathrm{A} \mathrm{( \% )}$ & $\mathrm{B}(\%)$ & \\
\hline 0 & 98 & 2 & 0.4 \\
1.5 & 87 & 13 & 0.8 \\
4.0 & 87 & 13 & 0.8 \\
5.0 & 80 & 20 & 0.8 \\
6.0 & 80 & 20 & 0.8 \\
8.0 & 55 & 45 & 0.5 \\
11.0 & 20 & 80 & 0.5 \\
\hline
\end{tabular}

Analysis was performed using the multiple reaction monitoring (MRM) mode. MRM transitions and crucial compounddependent parameters are listed in Table S1 (in Electronic Supplementary Material, ESM).

UHPLC-MS/MS was used to confirm the qualitative identification of phenolic acids and flavonoids in fruits samples. For quantitative analysis, the phenolic acids and flavonoids were analyzed using UHPLC-UV. The identified polyphenols were quantified according to respective standard calibration curves.

\section{Sample Preparation}

The L. barbarum L. fruits were from local supermarket and in herbalist's shop. The samples were protected against sunlight and stored at $4{ }^{\circ} \mathrm{C}$ before conducting the analyses.

The fruit samples $(1.0 \mathrm{~g})$ were first grounded, homogenized, then mixed with $20 \mathrm{~mL}$ of $50 \%$ methanol and agitated in an ultrasonic water bath for $20 \mathrm{~min}$. The resulted mixture was filtered and the residue was re-extracted twice under the same conditions. After the third extraction, the filtered solutions were combined and transferred into a flask. Then the sample was evaporated to volume about $15 \mathrm{~mL}$ and dissolved in $100 \mathrm{~mL}$ of deionized water, adjusted to $\mathrm{pH} 3.5$ by hydrochloric acid.

A solid-phase extraction vacuum station (BAKERBOND spe-12G system, J.T. Baker Inc., Deventer, Netherlands) and polymeric BOND Elut PLEXA cartridge (Agilent Technologies, USA) were used for the extraction of polyphenols. For purification, a BOND Elut PLEXA cartridge was pre-activated with $5 \mathrm{~mL}$ of methanol and equilibrated with $5 \mathrm{~mL}$ of acidified deionized water ( $\mathrm{pH}$ 3.5). Then, sample extract was passed through the sorbent at a flow rate of approximately $2 \mathrm{~mL} \mathrm{~min}^{-1}$, and the solid phase was air-dried for $2 \mathrm{~min}$. The analytes were eluted with $5 \mathrm{~mL}$ of methanol and the eluate evaporated to dryness. The dry residue was dissolved in $1 \mathrm{~mL}$ of mobile phase $(0.05 \%$ TFA in water:acetonitrile $(90: 10 ; v / v))$, filtered through a $0.2-\mu \mathrm{m}$ membrane filter, and $2 \mu \mathrm{L}$ injected into the UHPLC-UV system. The extraction procedure was performed in triplicate for each sample.

\section{Scavenging of DPPH'-Free Radical}

The method of Kao and Chen (2006) was used. One mL of L. barbarum L. fruit extract was mixed with a $0.2 \mathrm{~mL}$ of $1 \mathrm{mM}$ DPPH $^{*}$ solution (in methanol), and next the solution was mixed and then stood in the dark for $30 \mathrm{~min}$, and the absorbance was measured at $517 \mathrm{~nm}$. The scavenging effect (percent) was determined using the formula described by Kao and Chen (2006). 


\section{Method Validation}

The analytical procedure was validated, and the following validation parameters were evaluated: linearity, precision, accuracy, repeatability, and limits of detection and quantification.

The linearity was evaluated by three injections for each concentration by an appropriate dilution of the stock solutions to yield six concentrations and plotted using linear regression of the mean peak area/mean IS peak area versus analyte concentration by the least squares regression method. The data obtained were used for regression analysis, and correlation coefficients were calculated for each compound using Excel (Microsoft).

The limit of quantification (LOQ) was assessed as the lowest concentration on the calibration curve that could be quantitatively determined with an acceptable precision of less than $20 \%$ and accuracy within $\pm 20 \%$. The LOQ was established on the basis of six independent replicates of the QC samples within three consecutive validation days.

The precision of the method was estimated by the evaluation of the intra-day and inter-day precision using standard solutions containing polyphenols at the concentrations covering the entire calibration range (LQC: $1.0-$ $1.5 \mu \mathrm{g} \mathrm{mL}^{-1}$, MQC: $10.0-15.0 \mu \mathrm{g} \mathrm{mL}^{-1}$, and HQC: $16.7-20.0 \mu \mathrm{g} \mathrm{mL}^{-1}$ ). The intra-day precision was examined by a set of six replicate analyses of a given sample solution in a single day, and inter-day precision was determined by a set of six replicate analyses of the same samples in three consecutive days. The relative standard deviation (\%RSD) was taken as a measure of precision. The repeatability of the method was evaluated by the injection of six different samples prepared by the same procedure. The $\%$ RSD of retention time and component content for the 20 phenolic compounds was used to estimate the repeatability.

Accuracy was evaluated by the recovery experiments. However, it is difficult to get a good estimation of the true recovery due to lack of blank matrix. Three different concentrations constituting low, medium, and high contents of the reference compounds were, respectively, added to L. barbarum L. fruit samples with the known amounts of polyphenols, and the samples were left for $24 \mathrm{~h}$ at room temperature. After then, the extraction procedure described in "Sample Preparation" was conducted, and the extracts were analyzed using the above-described UHPLC-UV method. The quantity of each component was subsequently obtained by use of the corresponding calibration plots. Each set of samples was repeated three times. The percentage recoveries were evaluated by calculating the ratio of detected amounts (determined amount minus original amount) versus the added amounts.

\section{Results and Discussion}

\section{Chromatographic Method Development}

Initially, in our studies, an ultra-performance liquid chromatography methods with UV or MS/MS detection and gas chromatography method with MS detection (GCMS) were developed for determination of flavonoids and metabolites in human urine samples (Baranowska and Magiera 2011; Baranowska et al. 2011; Magiera et al. 2011; Magiera et al. 2012). However, these methods were not suitable for the simultaneous determination of selected polyphenol compounds in L. barbarum L. fruits.

Chromatographic separation of polyphenolic compounds was carried out on the $\mathrm{C} 18, \mathrm{C} 8$, and diphenyl columns. Finally, Poroshell 120-EC C18 column was used for separation of selected polyphenols. This column, due to the unique superficially porous particle and $2.7-\mu \mathrm{m}$ particle size, provides high resolution of tested analytes. In addition, this column enabled to obtain robust symmetrical peaks and higher sensitivity of the method compared to other columns.

Due to the wide range of polarity of phenolic compounds, a gradient elution system was developed. Different mobile phases were tested to optimize analytical performance. Acetonitrile, instead of methanol, was found to improve the resolution of flavonoids and phenolic acids. The addition of trifluoroacetic acid was proved to enhance the sensitivity and to get better peak shape.

Easily ionizing ability of phenolic hydroxyl groups makes the tailing phenomenon at the end of the standard peaks. By adding trifluoroacetic acid, all the standard peaks were separated successfully. Finally, acetonitrile-water with $0.05 \%$ trifluoroacetic acid in gradient elution mode was employed, and low background noise and suitable retention time were provided. In addition, different temperatures were tested $(15,20,30$, and $40{ }^{\circ} \mathrm{C}$ ) to improve the separation. Although lower temperatures allowed a better separation for QUE, HSD, and NHSD, the rest of determined compounds were not resolved, and lower temperatures led to an increase of the system backpressure. Thus, a temperature of $30{ }^{\circ} \mathrm{C}$ was selected as a compromise between the best resolution and a moderate pressure. The spectral bands of the studied compounds were obtained by their spectral array between 190 and $600 \mathrm{~nm}$, and the detection wavelength was chosen near to the absorption maximum. The detection was routinely carried out by monitoring the absorbance signals at 230, 260, 285, and $310 \mathrm{~nm}$. The use of different detection wavelengths ensured the compromise between selectivity and sensitivity. As shown in Fig. 1, each chromatographic run was completed within $11.0 \mathrm{~min}$. 
Fig. 1 UHPLC-UV

chromatogram of a standard solution containing the analyzed polyphenols and IS $(\lambda=230 \mathrm{~nm})$

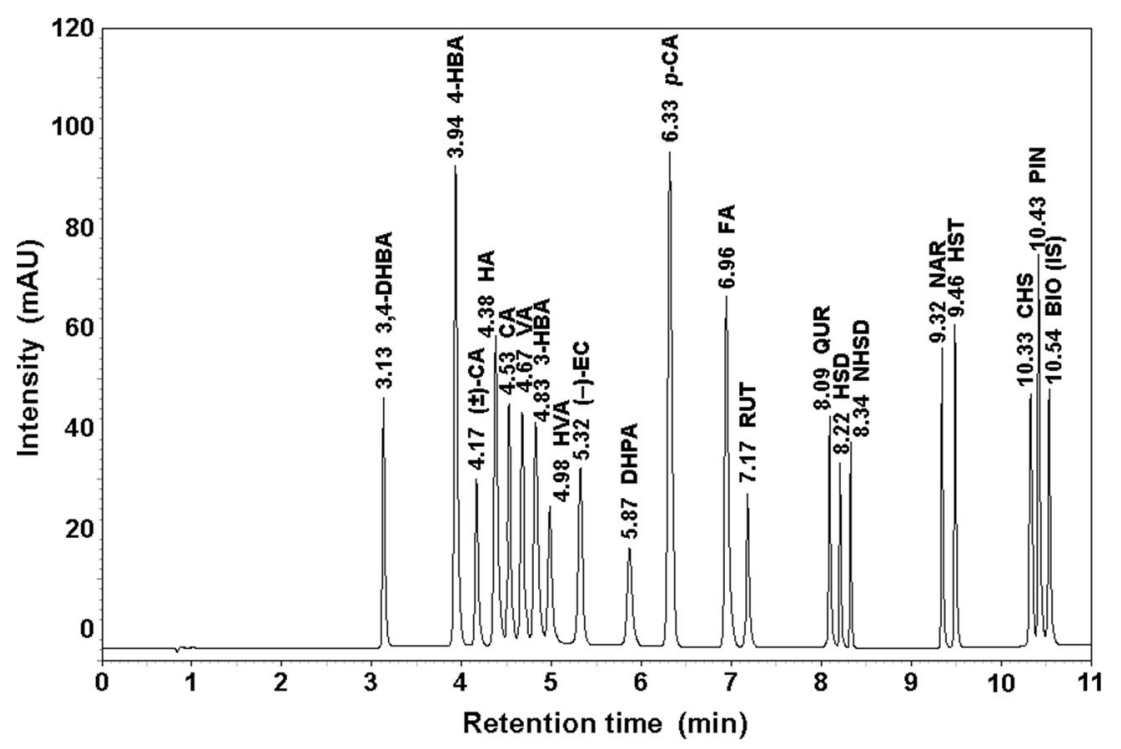

\section{Selection of Extraction and Clean-up Conditions}

The variables considered during this extraction process include extraction solvent, the length of extraction, and the number of extraction cycles, which have been considered for variation in other ultrasound-assisted extraction (UAE) method development research. Various solvents including methanol, ethanol, acetonitrile, ethyl acetate, and their mixture in water were tested for the extraction of polyphenols from fruit sample. Ethanol, acetonitrile, and their mixture with water were the effective extraction solvent, which resulted in the coextraction of lots of compounds. The chromatograms obtained for L. barbarum L. fruits using the extract from ethanol, acetonitrile, or their water solutions presented many interfering peaks, which overloads the column. On the other hand, ethyl acetate was not effective for extracting flavonoids from
Table 2 Regression data, LODs, LOQs, and recovery for studied compounds

\begin{tabular}{lllllll}
\hline Compound & Regression equation & $R^{2}$ & $\begin{array}{l}\text { Linear range } \\
\left(\mu \mathrm{g} \mathrm{mL} \mathrm{m}^{-1}\right)\end{array}$ & $\begin{array}{l}\text { LOD } \\
\left(\mu \mathrm{g} \mathrm{mL} \mathrm{m}^{-1}\right)\end{array}$ & $\begin{array}{l}\text { LOQ } \\
\left(\mu \mathrm{g} \mathrm{mL} \mathrm{m}^{-1}\right)\end{array}$ & $\begin{array}{l}\text { Recovery } \\
(\%)\end{array}$ \\
\hline 3.4-DHBA & $\mathrm{y}=0.11 \mathrm{x}+0.023$ & 0.997 & $0.2-20$ & 0.07 & 0.2 & 76.5 \\
4-HBA & $\mathrm{y}=0.188 \mathrm{x}+0.003$ & 0.999 & $0.3-30$ & 0.1 & 0.3 & 91.2 \\
$( \pm)$-CA & $\mathrm{y}=0.075 \mathrm{x}+0.016$ & 0.999 & $0.2-20$ & 0.07 & 0.2 & 53.9 \\
HA & $\mathrm{y}=0.132 \mathrm{x}+0.009$ & 0.999 & $0.3-30$ & 0.1 & 0.3 & 92.0 \\
CA & $\mathrm{y}-0.132 \mathrm{x}+0.009$ & 0.996 & $0.2-20$ & 0.07 & 0.2 & 95.3 \\
VA & $\mathrm{y}=0.086 \mathrm{x}-0.002$ & 0.999 & $0.3-30$ & 0.1 & 0.3 & 109 \\
3-HBA & $\mathrm{y}=0.076 \mathrm{x}+0.001$ & 0.998 & $0.3-30$ & 0.1 & 0.3 & 93.5 \\
HVA & $\mathrm{y}=0.045 \mathrm{x}+0.019$ & 0.999 & $0.3-30$ & 0.1 & 0.3 & 94.6 \\
$(-)$-EC & $\mathrm{y}=0.077 \mathrm{x}+0.017$ & 0.998 & $0.3-30$ & 0.1 & 0.3 & 55.8 \\
DHPA & $\mathrm{y}=0.049 \mathrm{x}+0.002$ & 0.999 & $0.3-30$ & 0.1 & 0.3 & 100 \\
$p$-CA & $\mathrm{y}=0.109 \mathrm{x}+0.021$ & 0.998 & $0.3-30$ & 0.1 & 0.3 & 87.1 \\
FA & $\mathrm{y}=0.091 \mathrm{x}+0.009$ & 0.999 & $0.3-30$ & 0.1 & 0.3 & 83.5 \\
RUT & $\mathrm{y}=0.246 \mathrm{x}+0.032$ & 0.997 & $0.3-30$ & 0.1 & 0.3 & 92.4 \\
QUR & $\mathrm{y}=0.165 \mathrm{x}+0.019$ & 0.999 & $0.3-30$ & 0.1 & 0.3 & 95.7 \\
HSD & $\mathrm{y}=0.053 \mathrm{x}+0.028$ & 0.997 & $0.2-20$ & 0.07 & 0.2 & 92.0 \\
NHSD & $\mathrm{y}=0.046 \mathrm{x}+0.005$ & 0.998 & $0.2-20$ & 0.07 & 0.2 & 93.1 \\
NAR & $\mathrm{y}=0.054 \mathrm{x}+0.013$ & 0.999 & $0.2-20$ & 0.07 & 0.2 & 91.6 \\
HST & $\mathrm{y}=0.057 \mathrm{x}+0.002$ & 0.999 & $0.2-20$ & 0.1 & 0.3 & 90.8 \\
CHS & $\mathrm{y}=0.100 \mathrm{x}-0.018$ & 0.998 & $0.3-30$ & 0.1 & 0.3 & 68.7 \\
PIN & $\mathrm{y}=0.131 \mathrm{x}+0.013$ & 0.998 & $0.2-20$ & 0.07 & 0.2 & 82.3 \\
\hline
\end{tabular}


L. barbarum L. fruit samples. For the present method, it was found that optimal polyphenols extraction from fruits occurred when $50 \%$ methanol as the extraction solvent and three extraction cycles were used. The three extracts were then combined and run through the clean-up and pre-concentration steps.

Two different sorbents (Oasis HLB and BOND Elut PLEXA) were tested to improve clean-up conditions, whether they could extract 20 polyphenols in only one step. The extraction efficiency of these sorbents was determined by recovery experiments. Oasis HLB and BOND Elut PLEXA are both polymeric sorbents with a polar group in their structure. This property made them very suitable for extracting the selected compounds. Oasis HLB was chosen because of its demonstrated ability to retain polar compounds thanks to a pyrrolidone group in its structure (Fontanals et al. 2010). BOND Elut PLEXA, a new generation of polymeric SPE sorbent, is composed of particles with a water-wettable, hydroxylated ligand on the surface and a narrower particle size distribution. According to the supplier, a gradient of polarity on the polymer surface shunts small analytes to the more hydrophobic center of the polymer bead where they are retained.
The sample $\mathrm{pH}$ was studied to ensure the most suitable conditions for retaining all the analytes. It may be noted that some compounds $(( \pm)$-CA, $(-)$-EC, HST, CHS, PIN) were poorly retained in the Oasis HLB cartridge, when the sample $\mathrm{pH}$ was in acid conditions $(\mathrm{pH}=3.5)$, and it only showed a recovery of $10-60 \%$. In alkalized samples $(\mathrm{pH}=8.0)$, the following compounds such as HST, CHS, and PIN showed recoveries higher than $70 \%$; however, the recoveries of most other compounds (e.g., 3,4-DHBA, 4-HBA, HA, HVA, p-CA, FA) were between 2 and $10 \%$. In this case, some analytes should be extracted from the acidified sample and some from alkalized samples. This two-step procedure would be substantially more timeconsuming and would require the higher consumption of solvents. When the same study was done with BOND Elut PLEXA, the recoveries were even higher for all 20 analytes in acid conditions $(\mathrm{pH}=3.5)$, as can be seen in Table 2 (53.9-109\%), particularly for HST, CHS, and PIN (68.7-90.8\%). The use of BOND Elut PLEXA sorbent allows for single-step extraction of polyphenols from L. barbarum L. fruits with a good performance for all tested compounds. Both sorbents have a hydrophobic group in their structure, but the different characteristics previously mentioned give to BOND Elut PLEXA more
Table 3 Precision and repeatability data for studied compounds $(n=6)$

\begin{tabular}{|c|c|c|c|c|c|c|}
\hline \multirow[t]{3}{*}{ Compound } & \multicolumn{4}{|c|}{ Precision (\%RSD) } & \multicolumn{2}{|c|}{ Repeatability (\%RSD) } \\
\hline & \multicolumn{2}{|l|}{ Intra-day } & \multicolumn{2}{|l|}{ Inter-day } & \multirow[b]{2}{*}{ Retention time } & \multirow[b]{2}{*}{ Content } \\
\hline & Retention time & Peak area & Retention time & Peak area & & \\
\hline 3.4-DHBA & 0.12 & 2.7 & 0.14 & 4.3 & 0.13 & 5.7 \\
\hline 4-HBA & 0.20 & 3.0 & 0.25 & 4.1 & 0.21 & 4.9 \\
\hline$( \pm)-\mathrm{CA}$ & 0.17 & 3.5 & 0.24 & 3.8 & 0.20 & 3.5 \\
\hline HA & 0.19 & 3.2 & 0.32 & 4.3 & 0.17 & 4.5 \\
\hline $\mathrm{CA}$ & 0.10 & 2.2 & 0.21 & 4.4 & 0.25 & 3.8 \\
\hline VA & 0.17 & 2.3 & 0.30 & 1.8 & 0.21 & 2.8 \\
\hline 3 -HBA & 0.20 & 3.3 & 0.32 & 4.3 & 0.22 & 1.5 \\
\hline HVA & 0.19 & 3.5 & 0.31 & 3.4 & 0.24 & 6.9 \\
\hline$(-)-\mathrm{EC}$ & 0.21 & 4.0 & 0.25 & 4.3 & 0.20 & 2.4 \\
\hline DHPA & 0.19 & 3.3 & 0.23 & 4.0 & 0.16 & 3.2 \\
\hline$p$-CA & 0.15 & 2.2 & 0.29 & 4.8 & 0.17 & 1.2 \\
\hline FA & 0.14 & 0.5 & 0.25 & 2.2 & 0.14 & 4.0 \\
\hline RUT & 0.12 & 2.4 & 0.15 & 3.5 & 0.13 & 2.3 \\
\hline QUR & 0.19 & 3.1 & 0.21 & 4.7 & 0.12 & 1.7 \\
\hline HSD & 0.15 & 5.4 & 0.17 & 7.2 & 0.11 & 2.8 \\
\hline NHSD & 0.10 & 2.4 & 0.14 & 4.3 & 0.18 & 3.3 \\
\hline NAR & 0.17 & 3.5 & 0.30 & 4.3 & 0.15 & 5.5 \\
\hline HST & 0.22 & 2.4 & 0.24 & 4.9 & 0.14 & 7.7 \\
\hline CHS & 0.15 & 2.5 & 0.21 & 3.5 & 0.15 & 3.6 \\
\hline PIN & 0.19 & 2.3 & 0.32 & 4.3 & 0.21 & 1.7 \\
\hline
\end{tabular}


efficiency at retaining the compounds. Therefore, we have chosen Bond Elut PLEXA for the isolation of polyphenols from fruit samples.

\section{Method Validation}

The calibration curve of each compound was established by injecting 6 different concentrations of standard mixtures consisting of 20 phenolic acids, flavonoids, and IS. Table 2 shows linear calibration curve with $R^{2}$, linear range, limit of detection (LOD), and limit of quantification (LOQ) of each compound determined. As a result, the obtained linear range was adequate for all the compounds. The correlation coefficient for the standard compounds was higher than 0.991 , which gave a good linearity response for the developed method. The LODs were in the range of $0.07-0.10 \mu \mathrm{g} \mathrm{mL}^{-1}$ for phenolic acids and for the flavonoids. Having in regard low LODs and LOQs, it is reasonable to conclude that this method can be used for quantitative analysis in L. barbarum L. fruits.
The results of precision showed that the \%RSD of the intra- and inter-day for retention times was 0.10 to $0.22 \%$ and 0.14 to $0.32 \%$, and for peak areas was 0.5 to $5.4 \%$ and 1.8 to $7.2 \%$, respectively (Table 4 ). The repeatability $(\% \mathrm{RSD})$ for content of compounds was less than $4.2 \%$ and for retention time were less than $7.7 \%$ (Table 3).

As shown in Table 2, recovery of the analytes ranged from 53.9 to $109 \%$ and the \%RSDs were less than $8.2 \%$. The above results demonstrate that the HPLC method is precise, accurate, and sensitive for the quantitative determination of flavonoids and phenolic acids in L. barbarum L. fruit samples.

\section{Method Applicability}

Twelve samples of $L$. barbarum L. fruits were analyzed using established extraction method under the above UHPLC-UV conditions. For the purpose of this study, quantified results slightly above the previous constructed
Fig. 2 Representative chromatograms obtained for an extract of $L$. barbarum $\mathrm{L}$. fruits using the proposed UHPLC-UV method $(\lambda=230 \mathrm{~nm})$

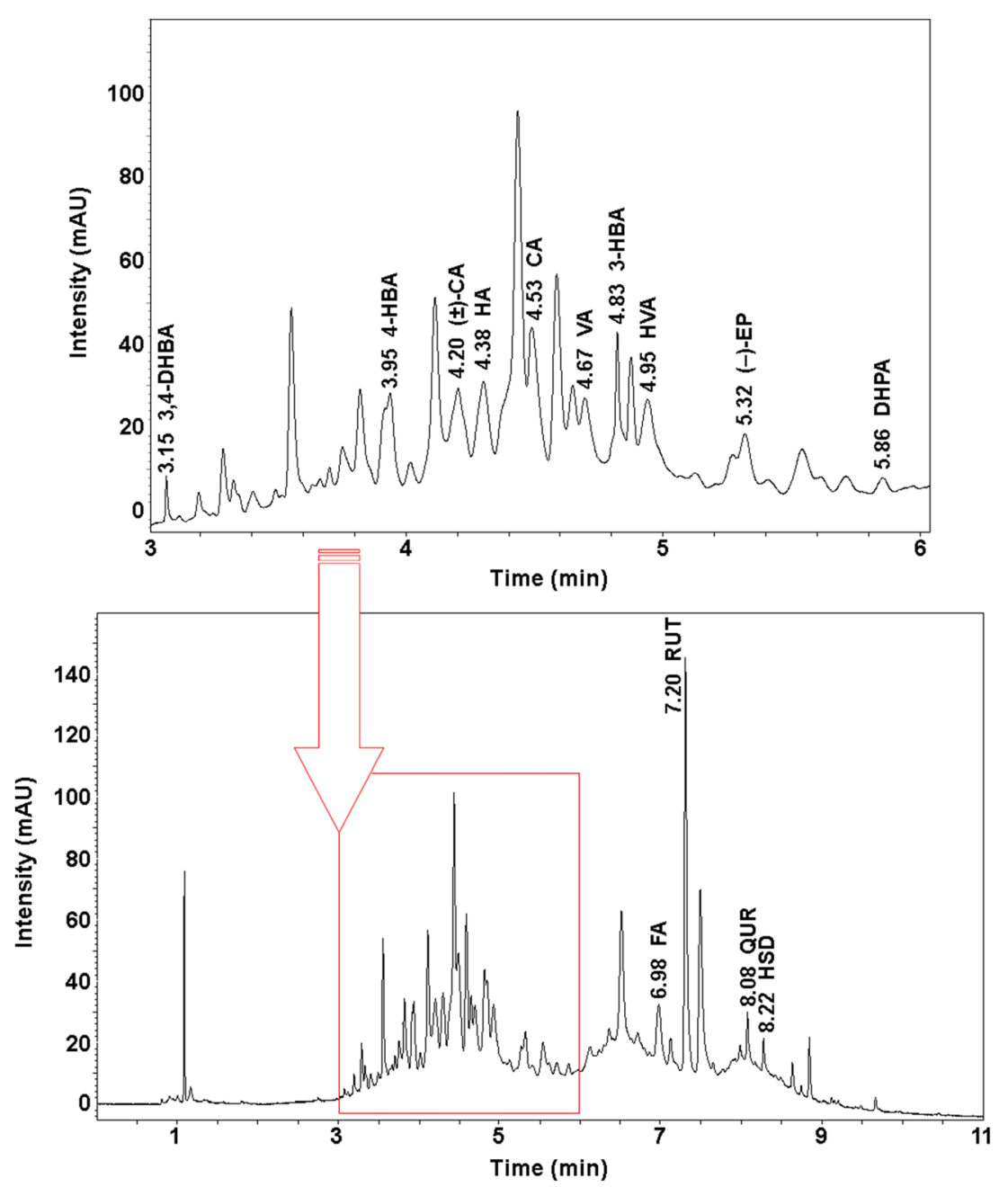


Fig. 3 Representative MRM chromatograms obtained for an extract of $L$. barbarum L. fruits using the proposed UHPLC-MS/ MS method
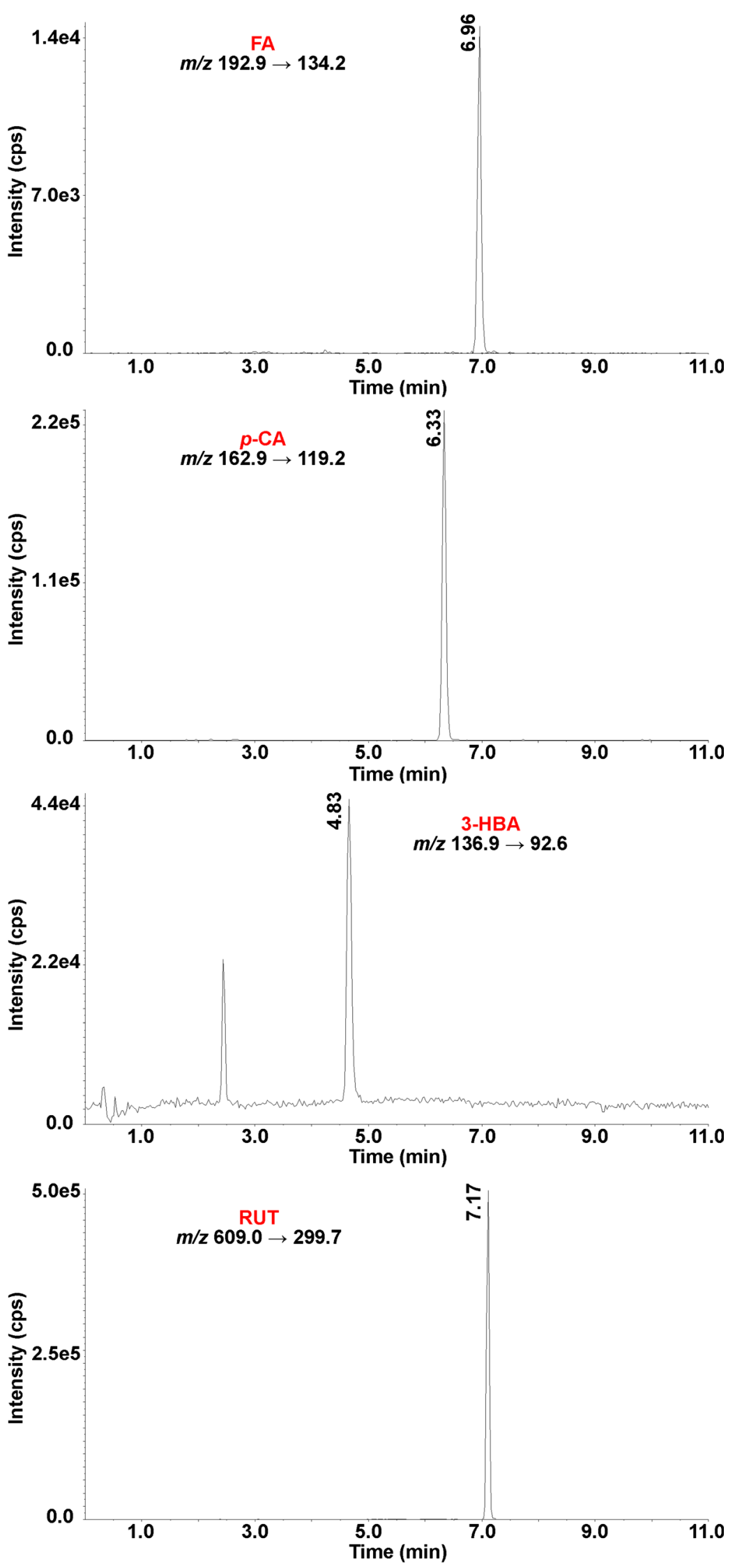
Table 4 Content of polyphenols determined in L. barbarum L. fruits by UHPLC-UV method and DPPH inhibition of the extract of $L$. barbarum L. fruits

\begin{tabular}{|c|c|c|c|c|c|c|c|c|c|c|c|c|c|c|c|c|}
\hline \multirow[t]{2}{*}{ Sample } & \multicolumn{15}{|c|}{ Content of polyphenols $\left(\mu \mathrm{g} \mathrm{g}^{-1}\right)$} & \multirow{2}{*}{$\begin{array}{l}\mathrm{DPPH}^{\circ} \\
\text { inhibition } \\
(\%)\end{array}$} \\
\hline & 3.4-DHBA & 4-HBA & $( \pm)-\mathrm{CA}$ & $\mathrm{CA}$ & VA & 3-HBA & HVA & $(-)-\mathrm{EC}$ & DHPA & HA & $p$-CA & FA & RUT & QUR & HSD & \\
\hline S1 & 1.36 & 0.99 & 40.6 & 8.45 & 43.8 & 28.6 & 15.6 & 45.0 & 6.47 & 10.1 & 1.32 & 10.2 & 2.85 & 10.8 & 3.74 & 49.8 \\
\hline S2 & 2.55 & 1.94 & 37.5 & 7.61 & 40.0 & 9.70 & 14.2 & 30.0 & 4.53 & 11.0 & 0.77 & 17.3 & 3.50 & 6.37 & 0.22 & 41.3 \\
\hline S3 & 1.74 & 2.01 & 49.0 & 5.45 & 31.7 & 5.97 & 22.0 & 54.5 & 3.50 & 27.3 & 1.51 & 15.7 & 2.24 & 21.7 & 0.25 & 40.5 \\
\hline S4 & 1.90 & 2.30 & 62.9 & 12.3 & 27.9 & 19.1 & 24.1 & 22.6 & 2.70 & 6.74 & 0.95 & 10.5 & 4.48 & 10.8 & 1.65 & 43.0 \\
\hline S5 & 1.72 & 1.71 & 39.3 & 11.0 & 36.0 & 13.2 & 15.0 & 53.5 & 2.71 & 18.2 & 1.21 & 27.0 & 4.16 & 12.1 & 2.26 & 49.3 \\
\hline S6 & 5.15 & 0.80 & 38.4 & 9.99 & 42.9 & 12.0 & 14.2 & 20.3 & 1.60 & 15.5 & 2.24 & 18.8 & 3.15 & 10.8 & 0.94 & 42.5 \\
\hline S7 & 1.27 & 0.25 & 31.0 & 9.90 & 54.2 & 13.3 & 15.7 & 24.2 & 7.49 & 8.5 & 1.54 & 19.5 & 7.31 & 9.95 & 0.62 & 54.9 \\
\hline S8 & 1.52 & 0.20 & 46.4 & 15.2 & 63.7 & 17.5 & 13.7 & 33.0 & 0.62 & 4.3 & 1.17 & 17.8 & 11.4 & 11.5 & 1.20 & 50.1 \\
\hline S9 & 1.63 & 0.15 & 37.0 & 11.3 & 58.9 & 19.7 & 14.0 & 38.5 & 1.91 & 7.1 & 1.05 & 16.2 & 6.07 & 11.1 & 0.84 & 51.1 \\
\hline $\mathrm{S} 10$ & 2.87 & 0.63 & 32.2 & 10.1 & 46.3 & 18.5 & 13.1 & 33.8 & 1.56 & 9.2 & 0.70 & 18.5 & 9.22 & 10.8 & 1.68 & 48.5 \\
\hline S11 & 1.70 & 0.31 & 29.1 & 9.62 & 40.1 & 16.9 & 12.2 & 43.2 & 5.27 & 12.3 & 2.32 & 16.3 & 10.0 & 12.6 & 2.45 & 46.5 \\
\hline S12 & 2.52 & 1.65 & 33.6 & 13.2 & 51.7 & 15.2 & 16.7 & 24.8 & 3.83 & 11.8 & 1.22 & 21.0 & 9.5 & 9.63 & 2.78 & 52.5 \\
\hline
\end{tabular}

calibration curves were confirmed by sample diluting. The identification of the studied compounds was performed by comparison of retention time and by the standard addition method. Figure 2 shows the typical chromatogram of L. barbarum L. fruit extract. Additionally, the identity of the flavonoids found to be present in the samples was confirmed by the UHPLC-MS/MS method in MRM mode (Fig. 3). The concentrations of phenolic compounds obtained in all studied samples are summarized in Table 4. Among the 15 positively identified compounds, VA was present in largest mass fraction $\left(63.7 \mu \mathrm{g} \mathrm{g}^{-1}\right)$, followed by $( \pm)$-CA $\left(62.9 \mu \mathrm{g} \mathrm{g}^{-1}\right),(-)$-EC $\left(54.5 \mu \mathrm{g} \mathrm{g}^{-1}\right), 3-\mathrm{HBA}$ $\left(28.6 \mu \mathrm{g} \mathrm{g}^{-1}\right)$, HA $\left(27.3 \mu \mathrm{g} \mathrm{g}^{-1}\right)$, FA $\left(27.0 \mu \mathrm{g} \mathrm{g}^{-1}\right)$, HVA $\left(24.1 \mu \mathrm{g} \mathrm{g}^{-1}\right)$, QUR $\left(21.7 \mu \mathrm{g} \mathrm{g}^{-1}\right), \mathrm{CA}$ (15.2 $\left.\mu \mathrm{g} \mathrm{g}^{-1}\right)$, RUT $\left(11.4 \mu \mathrm{g} \mathrm{g}^{-1}\right)$, DHPA $\left(7.49 \mu \mathrm{g} \mathrm{g}^{-1}\right)$, 3,4-DHBA $\left(5.15 \mu \mathrm{g} \mathrm{g}^{-1}\right)$, HSD $\left(3.74 \mu \mathrm{g} \mathrm{g}^{-1}\right), p$-CA $\left(2.32 \mu \mathrm{g} \mathrm{g}^{-1}\right)$, and 4-HBA $\left(2.30 \mu \mathrm{g} \mathrm{g}^{-1}\right)$. The remaining five compounds (NHSD, NAR, HST, CHS, PIN) were not detected in L. barbarum L. fruit extract. These results correspond with the previous studies (Inbaraj et al. 2010).

The radical-scavenging activity of fruit samples was assessed by using the $\mathrm{DPPH}^{\circ}$ method. $\mathrm{DPPH}^{\circ}$ radical-scavenging activity was quantified in terms of percentage inhibition of a pre-formed free radical by antioxidants in each fruit samples. The antioxidant activity of phenolic compounds are related to their chemical structure; it has been reported that compounds with a high number of present hydroxyl groups have higher activity. The contribution of each polyphenol to the antioxidant activity of L. barbarum L. fruits is different. So the activity of fruits depends on their phenolic profile. There was a significant variation in the percentage inhibition of the $\mathrm{DPPH}^{*}$ radical by the L. barbarum L. fruits (40.5-54.9\% inhibition) (Table 4).

\section{Conclusion}

In this study, a chromatographic method for the identification and quantification of 20 polyphenols compounds in L. barbarum L. fruits was developed. The separation was achieved by RP-UHPLC coupled with UV and MS/MS detectors. Both phenolic acids and flavonoids were isolated from the fruits of $L$. barbarum L. by extraction using $50 \%$ methanol and purification by a BOND Elut PLEXA polymeric reversed phase SPE cartridge. The precision, accuracy, and detection limits obtained for the phenolics quantified by this method enable its application to L. barbarum L. fruit extract analysis. Moreover, the proposed method showed sufficient separation which enables the quantification of selected polyphenols. The flavonoid extract showed the high effect in scavenging $\mathrm{DPPH}^{\circ}$. The results of this study can be applied to determine phenolic acid and flavonoid composition in both food and nutraceuticals.

Acknowledgments The authors thank Prof. Irena Baranowska for her very useful comments and suggestions during the preparation of this manuscript.

This project was partly supported by funds from the National Science Centre in the frame of the project PRELUDIUM No. 169964 (2011/03/N/ ST4/00732) for 2012-2014 period, Cracow, Poland. The research was performed with LC-MS/MS equipment purchased under the Silesian BIO-FARMA Project (Poland).

Conflict of Interest Sylwia Magiera declares that she has no conflict of interest. Michał Zaręba declares that he has no conflict of interest. This article does not contain any studies with human or animal subjects. 
Open Access This article is distributed under the terms of the Creative Commons Attribution 4.0 International License (http:// creativecommons.org/licenses/by/4.0/), which permits unrestricted use, distribution, and reproduction in any medium, provided you give appropriate credit to the original author(s) and the source, provide a link to the Creative Commons license, and indicate if changes were made.

\section{References}

Amagase H, Farnsworth NR (2011) A review of botanical characteristics, phytochemistry, clinical relevance in efficacy and safety of Lycium barbarum fruit (Goji). Food Res Int 44:1702-1717

Baranowska I, Magiera S (2011) Analysis of isoflavones and flavonoids in human urine by UHPLC. Anal Bioanal Chem 3999:3211-3219

Baranowska I, Magiera S, Baranowski J (2011) UHPLC method for the simultaneous determination of $\beta$-blockers, isoflavones and their metabolites in human urine. J Chromatogr B 879:615-626

Bravo L (1998) Polyphenols: chemistry, dietary sources, metabolism, and nutritional significance. Nutr Rev 56:317-333

Cartea ME, Francisco M, Soengas P, Velasco P (2011) Phenolic compounds in Brassica vegetables. Molecules 16:251-280

Cushnie TPT, Lamb AJ (2011) Recent advances in understanding the antibacterial properties of flavonoids. Int J Antimicrob Agents 38: 99-107

Daglia M (2012) Polyphenols as antimicrobial agents. Curr Opin Microbiol 23:174-181

Dong JZ, Lu DY, Wang Y (2009) Analysis of flavonoids from leaves of cultivated lycium barbarum L. Plant Foods Hum Nutr 64:199-204

Duan H, Chen Y, Chen G (2010) Far infrared-assisted extraction followed by capillary electrophoresis for the determination of bioactive constituents in the leaves of Lycium barbarum Linn. J Chromatogr A 1217:4511-4516

Fontanals N, Marcé RM, Borrull F (2010) Overview of the novel sorbents available in solid-phase extraction to improve the capacity and selectivity of analytical determinations. Contrib Sci 6:199-213

Harborne JB, Williams CA (2000) Advances in flavonoid research since 1992. Phytochemistry 55:481-504

He N, Yang X, Jiao Y, Tian L, Zhao Y (2012) Characterisation of antioxidant and antiproliferative acidic polysaccharides from Chinese wolfberry fruits. Food Chem 133:978-989
Inbaraj BS, Lu H, Kao TH, Chen BH (2010) Simultaneous determination of phenolic acids and flavonoids in Lycium barbarum Linnaeus by HPLC-DAD-ESI-MS. J Pharm Biomed Anal 51:549-556

Kao TH, Chen BH (2006) Functional components in soybean cake and their effects on antioxidant activity. J Agric Food Chem 54:75447555

Le K, Chiu F, Ng K (2007) Identification and quantification of antioxidants in Fructus lycii. Food Chem 105:353-363

Magiera S, Uhlschmied C, Rainer M, Huck CW, Baranowska I, Bonn GK (2011) GC-MS method for the simultaneous determination of $\beta$ blockers, flavonoids, isoflavones and their metabolites in human urine. J Pharm Biomed Anal 56:93-102

Magiera S, Baranowska I, Kusa J (2012) Development and validation of UHPLC-ESI-MS/MS method for the determination of selected cardiovascular drugs, polyphenols and their metabolites in human urine. Talanta 30:47-56

Mulvihill EE, Huff MW (2010) Antiatherogenic properties of flavonoids: implications for cardiovascular health. Can J Cardiol 26:17A-21A

Nováková L, Matysová L, Solich P (2006) Advantages of application of UPLC in pharmaceutical analysis. Talanta 68:908-918

Potterat O (2010) Goji (Lycium barbarum and L. chinense): phytochemistry, pharmacology and safety in the perspective of traditional uses and recent popularity. Planta Med 76:7-19

Procházková D, Boušová I, Wilhelmová N (2011) Antioxidant and prooxidant properties of flavonoids. Fitoterapia 82:513-523

Qian JY, Liu D, Huang AG (2004) The efficiency of flavonoids in polar extracts of Lycium chinense Mill fruits as free radical scavenger. Food Chem 87:283-288

Scalbert A, Williamson G (2000) Dietary intake and bioavailability of polyphenols. J Nutr 130:2073S-2085S

Shalaby NMM, Abd-Alla HI, Ahmed HH, Basoudan N (2011) Protective effect of Citrus sinensis and Citrus aurantifolia against osteoporosis and their phytochemical constituents. J Med Plants Res 5:579-588

Wu WB, Hung DK, Chang FW, Ong ET, Chen BH (2012) Antiinflammatory and anti-angiogenic effects of flavonoids isolated from Lycium barbarum Linnaeus on human umbilical vein endothelial cells. Food Funct 3:1068-1081

Yao X, Peng Y, Xu LJ, Li L, Wu QL, Xiao PG (2011) Phytochemical and biological studies of lycium medicinal plants. Chem Biodivers 8: 976-1010 